\title{
Loss of Melanoma-associated Antigen-A1 (MAGE-A1) Reverses Docetaxel Resistance and Increases Apoptosis via p53-independent Pathway in Gastric Cancer
}

\author{
Chen Xie", Natalia Liem*, Foong Ying Wong, Fui Leng Yan and Wei Peng Yong*
}

National University Health System, Department of Oncology and Haematology, Singapore

"These authors contributed equally to the study

\begin{abstract}
Melanoma Associated Antigen (MAGE)-encoding genes have been shown to be aberrantly expressed in various tumour types, and correlate with tumour progression and resistance to docetaxel. The objective of this study was to elucidate the regulatory mechanism underlying MAGE-A1 related docetaxel resistance in gastric cancer cells. Gastric cell lines with high docetaxel IC had higher expression of MAGE-A1 compared to cell lines with low docetaxel IC ${ }_{50}(p=0.0299)$. Knockdown of MAGE-A1 expression also resulted in an accumulation of cell populations in the G2/M phase of the cell cycle. An increased sensitivity to docetaxel was also observed in MAGE-A1 knockdown gastric cell line compared to its parental cell line. Loss of MAGE-A1 expression led to an increased expression of $\beta$-III tubulin, microtubule associated proteins, MAP4, and activation of apoptotic genes, p21, Bax and Bcl-2. Significant inverse correlation was observed between MAGE-A1 expression and its methylation in the gastric cancer cell lines. Collectively, our study demonstrated the expression of MAGE-A1 was regulated by methylation, and contributed to docetaxel sensitivity in gastric cancer cell lines through modulation of microtubules and proteins involving the apoptotic pathway.
\end{abstract}

Keywords: Melanoma associated antigen; Apoptotic genes; Docetaxel

\section{Introduction}

MAGE-A1 (melanoma associated antigen-A1) is a member the MAGE gene family and is located in the chromosome $\mathrm{X}$ [1]. Although the biological function of MAGE-A1 is not well understood, it appears that MAGE-A1 has a role in cell cycle regulation. Loss of MAGE-A family expression induced apoptosis and cell cycle arrest, in a p53 dependent manner via the activation of proapoptotic Bax [2]. MAGE-A1 is often silent in normal tissues except in the testis and placenta, but overexpression of MAGE-A1 has been observed in several cancers [3-5] including gastric cancer [6-8]. Furthermore, studies have observed that promoter methylation of MAGE-A1 inversely correlates to its gene expression, suggesting an epigenetic modulation may be involved in regulating MAGE-A1 expression $[3,8]$.

Several clinical studies have demonstrated that MAGE-A1 expression is associated with more advanced disease and shorter survival in patients with advanced gastric and colorectal cancer $[8,9]$. In addition, increased MAGE-A1 expression is associated with poorer treatment outcomes to taxane based chemotherapy in gastric cancer [10], while in vitro studies suggested that MAGE-A expressing cells may mediate drug resistance via p53 degradation and upregulation of survivin [11].

Docetaxel is highly active in gastric cancer and is often used in combination with other chemotherapeutic agents in advanced and recurrent gastric cancer [12-17]. Docetaxel belongs to the taxane family and is a microtubule-stabilizing agent that binds to $\beta$ tubulins, preventing the depolymerization of microtubules. The stabilisation of microtubules from docetaxel binding prevents the normal mitotic spindle formation and inhibits cell division [18]. Recently, overexpression of $\beta$ III tubulin has been implicated with docetaxel resistance in several types of cancers $[19,20]$, suggesting a role of $\beta$ III tubulin as a biomarker for chemotherapy response to docetaxel treatment [20].
In this study, we evaluated the associations between MAGE-A1 methylation status and expression with treatment response to antimitotic agent docetaxel, in gastric cancer cell lines. To understand the underlying mechanisms for docetaxel resistance in gastric cancer, we examine the effect of MAGE-A1 expression on cell cycle, microtubules and proteins in the apoptotic pathway using a MAGE-A1 knockdown gastric cancer cell line.

\section{Material and Methods}

\section{Cell lines and reagents}

Gastric cancer cell lines: AGS and KATO III were purchased from ATCC, USA. SNU601, SNU620 and SNU638 were purchased from Korean Cell Line Bank, Korea. IM95, OCUM1, NUGC3 and NUGC4 were purchased from Health Science Research Resources Bank, Japan. AZ521, MKN1, MKN28, MKN45 and SCH were obtained from DUKE NUS, Singapore. All 14 gastric cell lines were cultured at $37^{\circ} \mathrm{C}$ in humidified atmosphere containing $5 \% \mathrm{CO}_{2}$ and maintained in RPMI 1640 medium (Gibco; Grand Island, NY) containing 10\% heat inactivated fetal bovine serum (Gibco; Grand Island, NY) and 1\% penicillin/streptomycin (Gibco; Grand Island, NY).

${ }^{*}$ Corresponding author: Wei Peng Yong, Senior Consultant, National University Cancer Institute, Singapore, National University Hospital, Department of Haematology-Oncology, NUHS Tower Block, 1E, Kent Ridge Road, Singapore 119228, Tel: +65 96540060; E-mail: wei_peng_yong@nuhs.edu.sg

Received September 25, 2013; Accepted November 15, 2013; Published November 21, 2013

Citation: Xie C, Liem N, Wong FY, Yan FL, Yong WP (2013) Loss of Melanomaassociated Antigen-A1 (MAGE-A1) Reverses Docetaxel Resistance and Increases Apoptosis via p53-independent Pathway in Gastric Cancer. J Carcinog Mutagen S6: 006. doi:10.4172/2157-2518.S6-006

Copyright: (c) 2013 Xie C, et al. This is an open-access article distributed unde the terms of the Creative Commons Attribution License, which permits unrestricted use, distribution, and reproduction in any medium, provided the original author and source are credited. 
Citation: Xie C, Liem N, Wong FY, Yan FL, Yong WP (2013) Loss of Melanoma-associated Antigen-A1 (MAGE-A1) Reverses Docetaxel Resistance and Increases Apoptosis via p53-independent Pathway in Gastric Cancer. J Carcinog Mutagen S6: 006. doi:10.4172/2157-2518.S6-006

\section{Drugs}

Docetaxel (Aventis Pharma S.A., France) was stored at $4^{\circ} \mathrm{C}$, Trichostatin A (TSA) and 5-Aza-2'-deoxycytidine (5'aza) (SigmaAldrich; St Louis, MO) were stored at $-20^{\circ} \mathrm{C}$. Cisplatin (Hopsira Australia Pty Ltd, Australia) and 5-Fluorouracil (Pharmachemie BV, Netherland) were stored at room temperature.

\section{Cell viability and proliferation assays}

To assess the chemosensitivity of tumor cells to docetaxel, cell viability was measured by MTS (Colorimetric CellTiter $96 \mathrm{AQ}_{\text {ue }}$ One Solution Cell Proliferation Assay) (Promega; WI, USA). Cell suspension was cultured in 96-well flat-bottomed microtiter plates at seeding density of $2 \times 10^{3}$ cells/well and incubated overnight. Drug treatments were carried out as follows: docetaxel $(0.001-100 \mu \mathrm{M})$. Microtiter wells containing tumour cells with no drug treatments were used as controls, and wells containing complete medium were used as blank controls. Cells were incubated for 72 hours before the addition of MTS solution $(1 \mathrm{mg} / \mathrm{mL}$ per well $)$ and absorbance was read at $550 \mathrm{~nm}$ using a spectrophotometric microplate reader (Bio-Rad; CA, USA). The percent cell viability to different drug concentrations was calculated as the inhibition rate of (mean absorbance of treated wells/mean absorbance of control wells $) \times 100 \%$. IC ${ }_{50}$ was calculated by GraphPad Prism v4.0 (GraphPad Software, Inc; CA, USA).

\section{Reverse transcription-PCR (RT-PCR)}

Total RNA was isolated from 14 gastric carcinoma cell lines with the RNeasy Plus Mini Kit (QIAGEN, USA). $5 \mu \mathrm{g}$ of isolated RNA was reverse-transcribed and amplified using GeneAmp ${ }^{\circ}$ RNA PCR Core Kit (Applied Biosystems, USA). The product was amplified with primer sequences as described in Table 1. For the amplification of MAGE-A1, PCR conditions were as follows: preheat at $94^{\circ} \mathrm{C}$ for $5 \mathrm{~min}$, then 35 cycles of $94^{\circ} \mathrm{C}$ for $30 \mathrm{~s}$, annealing at $64^{\circ} \mathrm{C}$ for $30 \mathrm{~s}$, and extension at $72^{\circ} \mathrm{C}$ for $60 \mathrm{~s}$, followed by a final $5 \mathrm{~min}$ extension at $72^{\circ} \mathrm{C}$. For amplication of GAPDH, PCR was as follows: preheat at $95^{\circ} \mathrm{C}$ for $10 \mathrm{~min}$, then 25 cycles of denaturation at $94^{\circ} \mathrm{C}$ for $30 \mathrm{~s}$, annealing at $55^{\circ} \mathrm{C}$ for $30 \mathrm{~s}$, and extension at $72^{\circ} \mathrm{C}$ for $30 \mathrm{~s}$, followed by a final 10 min extension at $72^{\circ} \mathrm{C}$. Reverse transcription-PCR products were separated on $2 \%$ agarose and bands were visualized.

\section{Bisulphite conversion and methylation-specific polymerase chain reaction (MSP)}

DNA was extracted from 14 gastric carcinoma cell lines with Puregene $^{\mathrm{ma}}$ DNA Isolation Kit (Gentra Systems, Minneapolis, MN). 500 ng of gastric cell line DNA, positive control DNA (CpGenome Universal Methylated DNA, Chemicon, CA, USA) and negative control Human Sperm DNA (HsD) were used for bisulphate conversion by using EZ DNA Methylation-Gold ${ }^{m}$ Kit (Zymo Research Corporation, USA) as per manufacturer protocol. Primers used for MSP reactions were as in Table 1. PCR was preformed for 40 cycles, each cycle consisted of denaturation at $94^{\circ} \mathrm{C}$ for $30 \mathrm{~s}$, annealing at $60^{\circ} \mathrm{C} / 58^{\circ} \mathrm{C}$ for $60 \mathrm{~s}$ for

\begin{tabular}{|c|c|c|c|}
\hline RT-PCR & MAGE-A1 & Forward & 5'-TGT GGG CAG GAG CTG GGC AA-3' \\
\hline & MAGE-A1 & Reverse & 5'-GCC GAA GGA ACC TGA CCC AG-3' \\
\hline & GAPDH & Forward & 5'-ATC TCT GCC CCC TCT GCT GA-3' \\
\hline & GADPH & Reverse & 5'-GAT GAC CTT GCC CAC AGC CT-3' \\
\hline MSP & MAGE-A1_M & Forward & 5'-ATT TAG GTA GGA TTC GGT TTT C-3' \\
\hline & MAGE-A1_M & Reverse & 5'-AAA CTA AAA CGT CTT CCC GCG-3' \\
\hline & MAGE-A1_UM & Forward & 5'-ATT TAG GTA GGA TTT GGT TTT T-3' \\
\hline & MAGE-A1_UM & Reverse & 5'-AAA CTA AAA CAT CTT CCC ACA-3' \\
\hline
\end{tabular}

methylated/unmethylated MAGE-A1, and extension at $72^{\circ} \mathrm{C}$ for $60 \mathrm{~s}$, followed by a final $7 \mathrm{~min}$ extension at $72^{\circ} \mathrm{C}$. The PCR products were separated on a $2 \%$ agarose gel.

\section{Drug treatment}

To investigate if DNA promoter methylation is the regulation for MAGE-A1 expression, we treated cell lines of SNU601 and MKN1 with seeding density of 1E6 cells/plate. Cells were treated with 5'aza $(10 \mu \mathrm{M})$ for 72 hours and replenished every 24 hours with fresh medium; and TSA ( $500 \mathrm{nM}$ ) for 24 hours. The combination treatment was 5 'aza (10 $\mu \mathrm{M})$ for 72 hours and every 24 hours replenish with fresh medium, and then followed by TSA $(500 \mathrm{nM})$ for 24 hours. The MAGE-A1 expression was examined by RT-PCR.

\section{miRNA transfection}

The custom made primers for MAGE-A1 were purchased from Invitrogen. These miRNA gene double-strands were ligated with Block-It $^{\mathrm{ma}}$ Pol II miR RNAi Expression Vector Kits (K4936-00, Invitrogen, Germany) following the manufacturer's instruction. Then, the vector with MAGE-A1 miRNA or control miRNA plasmids were transfected into the MKN1 and MKN28 cells using Lipofectamine-2000 (Invitrogen, Germany) according to the manufacturer's instructions.

\section{Western blot and protein analysis}

Western blots were performed with primary antibodies; anti-MAGE-A1, anti-Bcl-2 and anti- $\beta$ III-tubulin (Santa Cruz Biotechnology; CA, USA); anti-p21 Waf1/Cip1 (12D1), anti-p53, antiBax, anti- $\alpha$-tubulin, anti- $\beta$-tubulin, anti-MAP4, and anti-GAPDH (Cell Signaling; MA, USA), secondary antibodies (anti-rabbit IgG, HRPLinked and anti-mouse IgG, HRP-Linked) were purchased from Cell Signaling Technology (Cell Signaling; MA, USA). Cells were washed with ice cold PBS and resuspended in lysis buffer (CelLytic; SigmaAldrich; St Louis, MO) and $20 \mu \mathrm{g}$ of protein was electrophoretically separated on $8 \%$ and $12 \%$ SDS-PAGE. The signals were visualized by ECL reagent (AmershamTM ECL Plus Western Blotting Detection System; GE Healthcare; Buckinghamshire, UK), followed by exposure to chemiluminescence film (Amersham HyperfilmTM ECL; GE Healthcare; Buckinghamshire, UK). Immunoblot analyses were repeated twice for each protein tested.

\section{Immunofluorescence staining}

Cells were seeded onto the 8 wells chamber slide and allowed to grow until $70 \%$ confluence. The cells were fixed by $200 \mu \mathrm{l} 4 \%$ formadehyde for 10 minutes and permeabilised by $200 \mu \mathrm{l} 0.1 \%$ Triton X100 in PBS (PBT) for 10 minutes. The blocking was done by incubating the cells with $200 \mu \mathrm{l}$ \% Bovine Serum Albumin in PBT for 1 hour. 1: 200 dilution of anti- $\beta$ tubulin antibody (Cell Signaling, MA, USA) was added into each well and incubate for overnight at $4^{\circ} \mathrm{C}$. Then 1: 250 dilution of Alexa Fluo 568 (Invitorgen, Germany) was added into each well and incubated for 1 hour in the dark. $10 \mu \mathrm{l}$ of Prolong Gold with DAPI (Invitorgen, Germany) was added into each well and air dried in the dark. The glass slide was sealed with a coverslip ready for imaging. Washing with PBS twice was required in between each step. The incubation was done at room temperature except the primary antibody incubation.

\section{Cell cycle analysis}

Cell cycle distribution of cells was analyzed using flow cytometry. Cells were fixed with $500 \mu \mathrm{l}$ of ice-cold $70 \%$ ethanol at $4^{\circ} \mathrm{C}$ overnight, and washed in 1x PBS before resuspending the cells in $500 \mu \mathrm{l}$ of $1 \mathrm{x}$ 
Citation: Xie C, Liem N, Wong FY, Yan FL, Yong WP (2013) Loss of Melanoma-associated Antigen-A1 (MAGE-A1) Reverses Docetaxel Resistance and Increases Apoptosis via p53-independent Pathway in Gastric Cancer. J Carcinog Mutagen S6: 006. doi:10.4172/2157-2518.S6-006

PBS with $100 \mu \mathrm{g}$ RNase (Qiagen) and $5 \mu$ l propidium iodide (BD Pharmingen $^{\mathrm{Tx}}$ ) for 15 minutes at room temperature. Cell cycle analysis was performed on a BD LSRII Analyser with BD FACSDiva software. 1 $\times 10^{4}$ cells were analyzed for each sample and the sub-G1 cell population was considered as apoptotic cells and debris was eliminated from the analysis using a forward and side scatter plot.

\section{Statistics}

The dosage increments were log-transformed, allowing equal horizontal spacing of data points on the dose response curve. Spline curve was plotted from fit spline/LOWESS analysis by GraphPad Prism v4.0 (GraphPad Software, Inc; CA, USA) and the drug concentration which resulted in $50 \%$ cell death was determined from the curve generated. The $\mathrm{IC}_{50}$ was calculated by the antilog of the value obtained.
All data were presented as mean \pm standard error (SE) from at least two independent experiments. $p$ values $<0.05$ were considered statistically significant.

\section{Results}

\section{Sensitivity of gastric cancer cell lines to docetaxel was associated with MAGE-A1 expression}

The mRNA expressions of MAGE-A1 were investigated in 14 gastric cancer cell lines by RT-PCR (Figure 1a); and the association of MAGE-A1 expression to the chemosensitivity of docetaxel, $\mathrm{IC}_{50}$ was determined using various docetaxel concentrations $(0.001$ to $100 \mu \mathrm{M})$ in all 14 gastric cell lines (Figure $1 \mathrm{~b}$ ). There was $100 \%(6 / 6)$ concordance between hypomethylated status and the presence MAGE-A1; $87.5 \%$

(a)

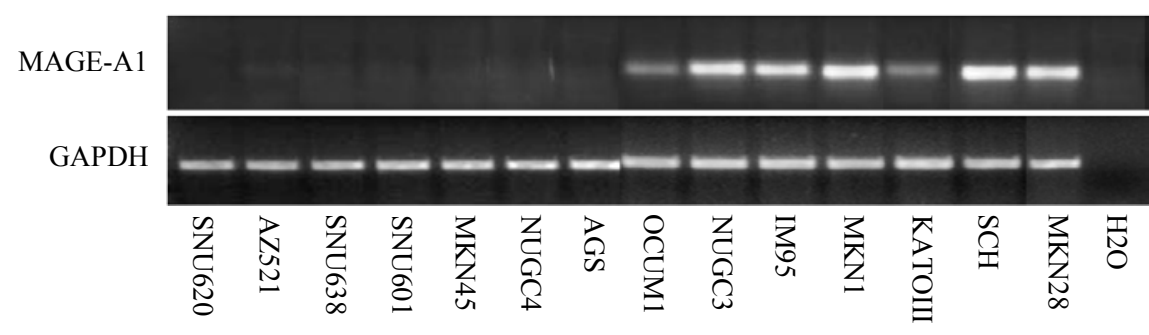

(b)

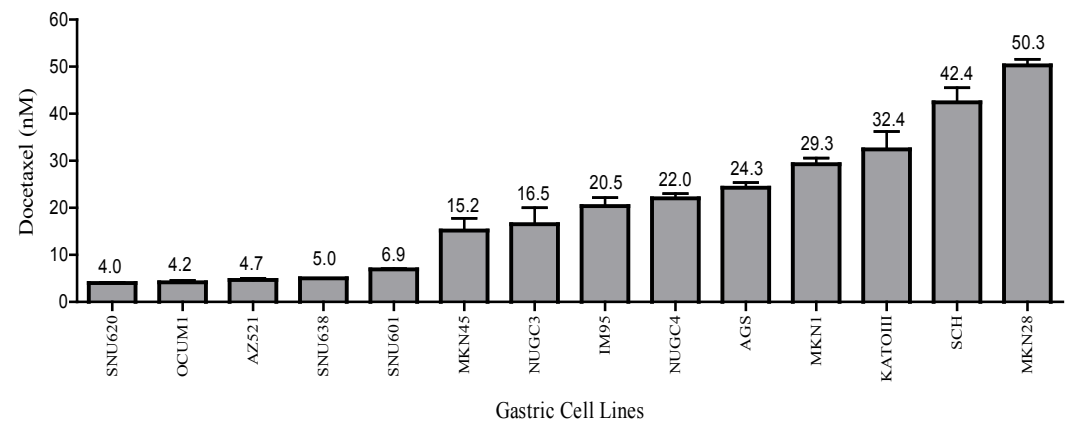

(c)

\section{MAGE-A1 expression VS docetaxel response $(\mathbf{p}=\mathbf{0 . 0 2 9 9})$}

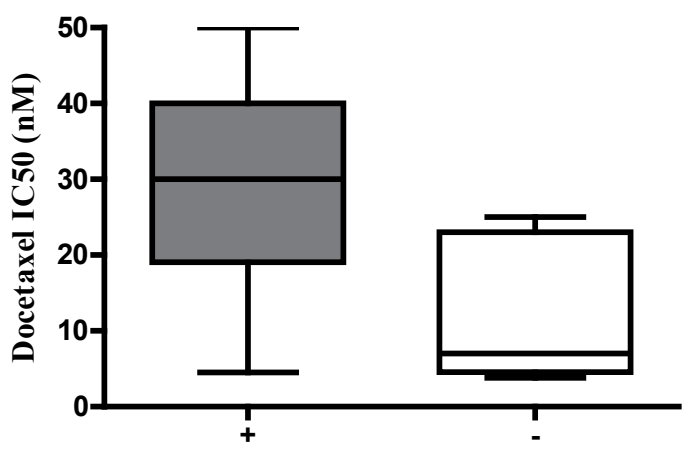

MAGE-A1 expression

Figure 1: (a) mRNA expression MAGE-A1 in 14 gastric cell lines by RT-PCR. mRNA expression of GAPDH was used as the baseline. At least two independent experiments were preformed for each cell line. (b) MTS assay of 14 cell lines ranked according to their docetaxel response (IC $\mathrm{C}_{50}$ ). Cells were treated with docetaxel over 72 hours. Experiments were performed in triplicates, and repeated in at least two independent experiments. (c) Box plots of GC cell lines based on MAGE-A1 expression and $I_{50}$ of docetaxel $(n=14) .5$ cell lines that had high IC ${ }_{50}$ to docetaxel $(n=7)$, had MAGE-A1 expression. 5 cell lines that had low/intermediate IC ${ }_{50}$ to docetaxel $(n=7)$ were no expression of MAGE-A1. ${ }^{*} p=0.0299$ is calculated by unpaired $t$ test with Welch correction. 
(7/8) concordance between methylated status and the absence of MAGE-A1. The median $\mathrm{IC}_{50}$ of docetaxel in cell lines expressing MAGE-A1 was found to be higher compared to cell lines that did not express MAGE-A1 $(28.64 \pm 5.66 \mathrm{nM}$ vs. $11.61 \pm 3.41 \mathrm{nM}, p=0.0299)$ (Figure 1c), suggesting that MAGE-A1 expression is associated with relative resistance to docetaxel in gastric cell lines.

\section{Loss of MAGE-A1 expression led to reversal of docetaxel} resistance but not to cisplatin or 5 fluorouracil $(5 \mathrm{FU})$

To investigate the role of MAGE-A1 expression to docetaxel treatment, MAGE-A1 expression was selectively knocked down via miRNA in two MAGE-A1 expressing cell lines that displayed docetaxel resistance (Figure 2). Transfected variants of MAGE-A1 showed loss of MAGE-A1 expression compared to their corresponding parental cell lines (Figure 2). Furthermore, cell lines that had loss MAGE-A1 expression were found to be more sensitive to docetaxel compared to their parental counterparts in both gastric cell lines (Table 2). To establish if the increased drug sensitivity in MAGE-A1 knockdown cell lines were specific to docetaxel, drug response studies using cisplatin and 5FU were carried out in these gastric cell lines. It was observed that selective knockdown of MAGE-A1 had no significant effects on cisplatin and 5FU sensitivity, and that altered drug sensitivity due to loss of MAGE-A1 expression was specific to docetaxel.

\section{Loss of MAGE-A1 expression led to accumulation of cells in} apoptotic phase when treated with docetaxel

Cell cycle profiles demonstrated fewer cell populations in the G2/M phase in the untreated MKN1 parental cell line and its scrambled control (Figure 3). In contrast, silencing MAGE-A1 expression resulted in a significant accumulation of cells in the S-phase and the late G2/Mphase (Figure 3). This cell cycle profile was similar to that observed in AZ521, a cell line that had low MAGE-A1 expression and was shown to be sensitive to docetaxel. Upon docetaxel treatment, a shift in the cell population to G2/M phase was observed in both the parental cells and scrambled control, suggesting that cells were undergoing mitosis despite drug treatment. Conversely, most cells appeared to be arrested at the G0/G1 phase in variant cell line that had lost MAGE-A1 expression (MKN1-V1) with a sub-population of cells undergoing apoptosis following docetaxel treatment (Figure 3). Interestingly, cell cycle profile differs between the docetaxel sensitive variant cell line that
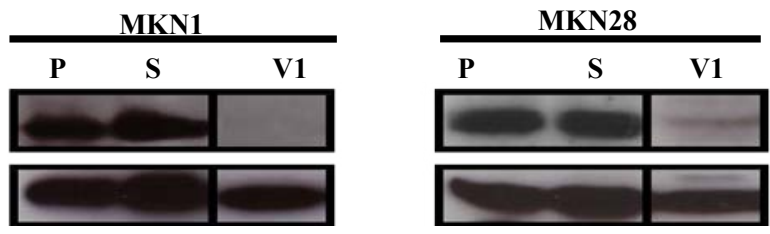

Figure 2: Immunoblot of MAGE-A1 expressions in MKN1 and MKN28 parental and knockdown variant cell lines. Knockdown variant of MAGE-A1 in MKN1 and MKN28 cell lines demonstrated loss in MAGE-A1 expression compared to its corresponding parental cell lines. P: Parental cell lines, V1: knockdown variants of MAGE-A1, S: scrambled controls. At least two independent experiments were preformed for each cell line.

\begin{tabular}{ll|l|l|l} 
MKN1 & MKN1-V & $p$ value MKN28 & MKN28-V & $p$ value
\end{tabular} $\begin{array}{llllllll}\text { DOC (nM) } 29.30 \pm 1.30 & 5.00 \pm 0.30 & 0.022 & 50.30 \pm 1.30 & 2.50 \pm 0.50 & <0.0001\end{array}$ \begin{tabular}{|l|l|l|l|l|l}
\hline $\mathbf{5 F U}(\mu \mathrm{M})>100$ & $>100$ & $2.43 \pm 0.07$ & $2.32 \pm 0.27$ & 0.820
\end{tabular} \begin{tabular}{ll|l|l|l|l|l|l|l}
\hline CIS $(\mu \mathrm{M})$ & $28.12 \pm 2.84$ & $29.05 \pm 0.86$ & 0.464 & $30.81 \pm 1.26$ & $31.67 \pm 1.08$ & 0.636
\end{tabular}

Table 2: MTS assay to determine $\mathrm{IC}_{50}$ of docetaxel, DOC; 5 fluorouracil, $5 \mathrm{FU}$; and Cisplatin, CIS in MKN1, MKN28 and their MAGE-A1 knockdown variant cell lines (MKN1-V1, MKN28-V1). $p$ value is calculated by unpaired t-test.
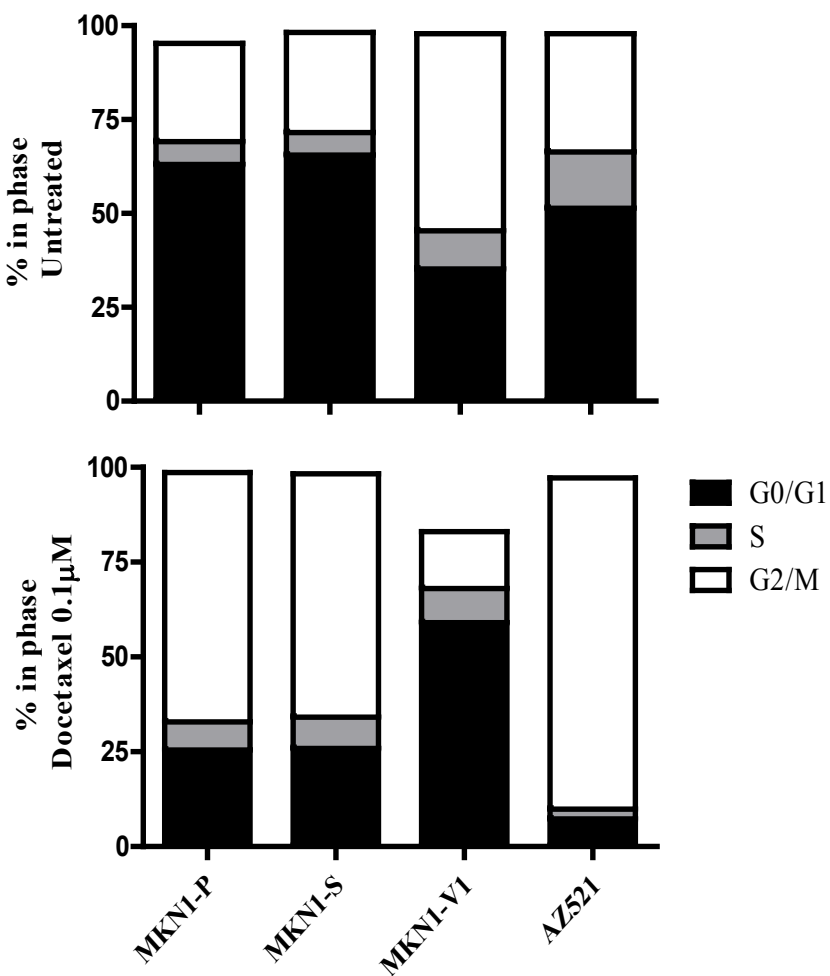

Figure 3: Cell proliferation profile in MKN1 parental, knockdown variant cell lines and AZ521 this is the docetaxel sensitive cell line. Treatment with docetaxel at $100 \mathrm{nM}$ for 24 hours. P: Parental cell lines, V1: knockdown variants of MAGE-A1, S: scrambled controls. At least 2 independent experiments were performed.

had loss MAGE-A1 expression (MKN1-V1) and another gastric cell line that was inherently sensitive to docetaxel (AZ521), whereby an increased shift of cell population to the G2/M phase was observed in AZ521 cells, indicative of cell cycle arrest being targeted by docetaxel, a drug that targets the G2/M phase of dividing cells.

\section{MAGE-A1 regulated expressions of tubulins and associated} microtubule proteins

Since the microtubules and their associated proteins are the targets of docetaxel, therefore, protein expression of tubulins and microtubule associated proteins were investigated. Although protein expression of total $\alpha$ and $\beta$ tubulins did not show differential expression between parental, scrambled or variant cell lines (Figure $4 \mathrm{a})$, immunofluorescence staining of total $\beta$ tubulins demonstrated bundling of $\beta$ tubulins in response to docetaxel in MAGE-A1 knockout cells (Figure 5). Conversely, $\beta$ tubulin networks appeared to be intact and unchanged in parental and scrambled control cells, regardless of docetaxel treatment (Figure 5). Increased expression of $\beta$ III tubulins as well as stabilizing microtubule associated proteins, MAP4 were also found to be associated with the loss of MAGE-A1 expression in variant cell lines but not in parental or scrambled controls, in contradistinction to the similarity of cell lines which had MAGE-A1 expression and low docetaxel sensitivity (Figure 4b).

\section{Upregulation of Bax and Bcl-2 in MAGE-A1 knockout variant cells}

As the loss of MAGE-A1 appears to affect the cellular response to drugs targeting cell cycle, the protein expression of important cell 
Citation: Xie C, Liem N, Wong FY, Yan FL, Yong WP (2013) Loss of Melanoma-associated Antigen-A1 (MAGE-A1) Reverses Docetaxel Resistance and Increases Apoptosis via p53-independent Pathway in Gastric Cancer. J Carcinog Mutagen S6: 006. doi:10.4172/2157-2518.S6-006



(b)

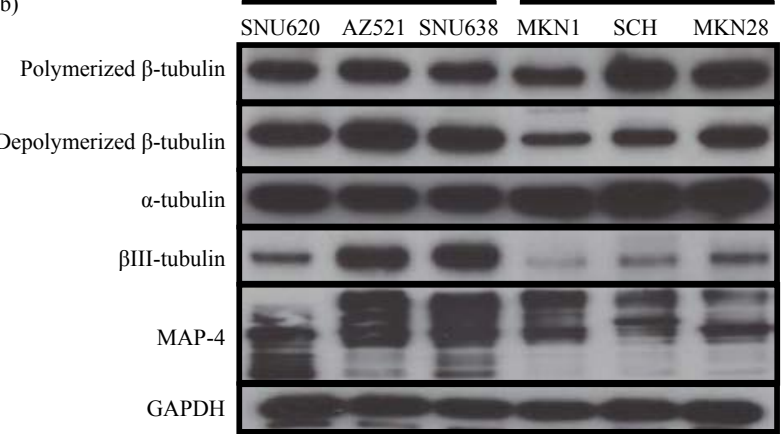

Figure 4: (a) Expressions of cell cycling genes in MKN1 parental cell line $(\mathrm{P})$ and its variant cell line (V1 and V2) in response to docetaxel treatment at $0.1 \mu \mathrm{M}$ after 24 hours incubation. S: scrambled control. (b) Expressions of cell cycling genes in docetaxel sensitive and resistant cell lines. At least two independent experiments were preformed for each cell line.



Figure 5: Immunofluorescence of $\beta$ tubulin in MKN1 parental $(P)$ and variant (V) cells in response to docetaxel treatment at $10 \mathrm{nM}$ after 2 hours incubation. $\mathrm{S}$ : scrambled control. At least two independent experiments were preformed for each cell line. cycle regulatory genes were investigated in relation to the expression of MAGE-A1 and response to docetaxel (Figure 6b). In comparison to parental cell line (P) that expressed MAGE-A1, the loss of MAGE-A1 expression in the variant cell lines (V1 and V2) led to an overexpression of Bcl-2 and Bax (Figure 6b), the same expression pattern of which were observed in docetaxel sensitive cell lines (Figure 6a).

It was also observed that there was a slight decrease in p53 levels in untreated MAGE-A1 knockout variant cell lines compared to parental or scrambled controls. However p53 levels remained at a similar level among all cell lines after docetaxel treatment, suggesting that the reverse of docetaxel resistance from the loss of MAGE-A1 expression was mediated via a p53-independent pathway (Figure $6 \mathrm{~b})$. Protein expressions of the Bcl-2 family members as well as p53 remained unchanged among cell lines after docetaxel treatment, with exception to p21, where increased p21 expression was observed in the variant cell lines after docetaxel treatment, suggesting that its role in regulating apoptosis in response to drug treatment may be involved with MAGE-A1 gene expression (Figure 6).

MAGE-A1 expression was predominately regulated by hypomethylation that correlated inversely with mRNA expression in gastric cell lines

The DNA promoter methylation statuses of MAGE-A1 were investigated in 14 gastric cancer cell lines by MSP respectively (Figure $7 \mathrm{a})$. Six gastric cell lines that were found to have MAGE-A1 expression were also unmethylated for this gene (Table 3 and Supplementary Table 1). Conversely, with exception to Kato III, 7 gastric cell lines

(a)



(b)

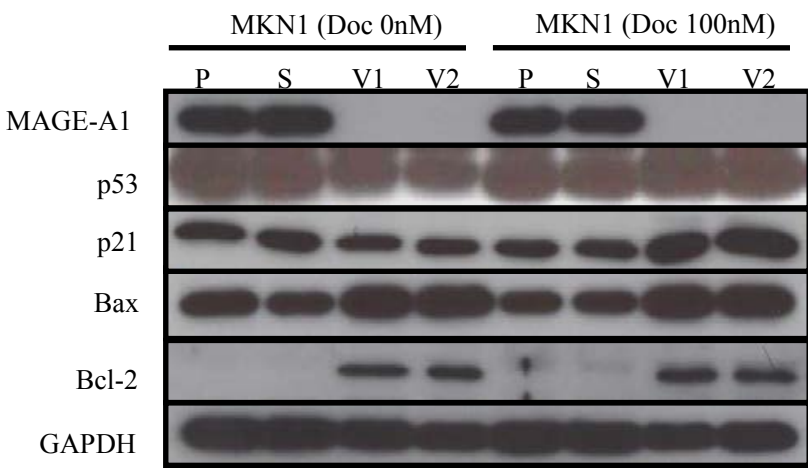

Figure 6: (a) Expressions of apoptotic genes in docetaxel sensitive and resistant cell lines. (b) Expressions of apoptotic genes in MKN1 parental cell line $(P)$ and its variant cell line $(V 1)$ in response to docetaxel treatment at 0.1 $\mu \mathrm{M}$ after 24 hours incubation. S: scrambled control. At least two independent experiments were preformed for each cell line. 
Citation: Xie C, Liem N, Wong FY, Yan FL, Yong WP (2013) Loss of Melanoma-associated Antigen-A1 (MAGE-A1) Reverses Docetaxel Resistance and Increases Apoptosis via p53-independent Pathway in Gastric Cancer. J Carcinog Mutagen S6: 006. doi:10.4172/2157-2518.S6-006

(a)


(b)
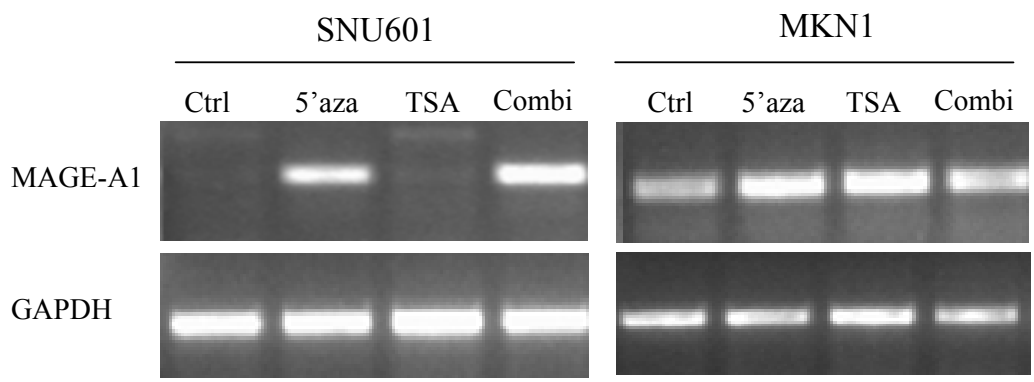

(c)

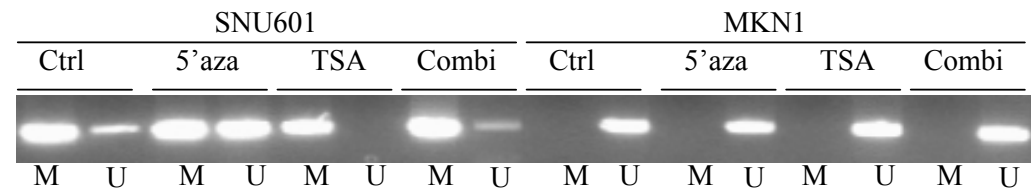

Figure 7: (a) DNA promoter methylation status of MAGE-A1 in 14 gastric cell lines by MSP. The presence of both methylation and unmethylation bands was considered as methylation. UniM: Universal methylated DNA is the control for methylation; HSD: human sperm DNA is the control sample for unmethylation. M: methylation; U: unmethylation. (b) mRNA expression and (c) methylation status of MAGE-A1 in cell lines treated with 5'aza and/or TSA. Cell lines with low docetaxel $I_{50}$ (SNU601) showed demethylation and re-expression of MAGE- A1 after 5'aza treatment but not in TSA. In contrast, MKN1 with high docetaxel IC ${ }_{50}$ showed no change in mRNA expression or methylation status in MAGE-A1 after all treatments. GAPDH expression was used as baseline. At least two independent experiments were preformed for each cell line.

that were methylated for MAGE-A1 showed absence for its mRNA expression. These results suggested an inverse correlation between MAGE-A1 methylation status and its expression in gastric cell lines, $p=0.0012$ (Table 3 and Supplementary Table 1).

To investigate the relative contribution of DNA promoter methylation and histone acetylation on MAGE-A1 expression, two cell lines (SNU 601 and MKN1) were selected based on their MAGE-A1 expression levels and treated with a demethylating agent 5 'azacytidine (5'aza) and/or HDAC inhibitor (TSA) (Figures 7b and 7c).

In MAGE-A1 non-expressing SNU601, demethylation of MAGE-A1 after 5'aza treatment, corresponded to the re-expression of MAGE-A1 (Figures 7b and 7c). However, the expression of MAGE-A1 was not affected after treatment with TSA, suggesting that epigenetic modulation of MAGE-A1 expression was predominantly mediated by methylation of MAGE-A1 promoter. Treatment with 5'aza and TSA did not alter methylation status or mRNA expression of MAGE-A1 in MAGE-A1 expressing MKN1 with unmethylated DNA promoter (Figures $7 \mathrm{~b}$ and $7 \mathrm{c}$ ).

\section{Discussion}

Clinically, increased MAGE-A1 expression has been associated with resistance to taxane-based chemotherapies in patients with gastric cancer [10,21]. Taxanes, such as docetaxel and paclitaxel stabilize microtubules, resulting in aberrant cell mitosis, G2/M phase arrest, and, eventually cell death [22]. We observed differences in cell cycle profiles among docetaxel-resistant gastric cell lines that expressed MAGE-A1 and non MAGE-A1 expressing cell lines that were more sensitive to docetaxel. In addition, the complete loss of MAGE-A1 expression in knocked down cell lines appeared to be more docetaxel sensitive, inducing cell cycle arrest early in the G1 phase, while shifting cells from the G2/M phase to cellular apoptosis.

It is also known that the loss of MAGE-A expression activates Bax and downregulates survivin through both p53-dependent and independent mechanisms [11]. In our study, we observed that the loss of MAGE-A1 expression resulted in increased Bax and Bcl-2 expressions but not $\mathrm{p} 21$ and $\mathrm{p} 53$, suggesting that upregulation of Bax was mediated through a p53-independent pathway. Docetaxel induces apoptotic pathways through the activation of $\mathrm{p} 21$ and Bax via both p53 dependent and independent mechanisms [23-25]. We have demonstrated that in MAGE-A1 knocked down cell lines, there was a greater increase in $\mathrm{p} 21$ after docetaxel treatment, suggesting that the loss of MAGE-A1 played a direct role in docetaxel response involving the activation of apoptosis regulatory genes. The p53 expression appeared unaffected after docetaxel treatment. This observation is similar to the result observed by Gan et al showing docetaxel stabilized p53 protein level and upregulated p21 in prostate cancer cells [25]. Although Bcl-2 was up-regulated following the knock down of MAGE-A1, it did not appear to affect docetaxel response. Several authors have reported similar findings and proposed Bcl-2 as marker for the M-phase events, 


\begin{tabular}{|c|c|c|}
\hline Methylation & Unmethylated & Methylated \\
\hline RNA expression & & \\
\hline +ve & 6 & 1 \\
\hline -ve & 0 & 7 \\
\hline
\end{tabular}

Table 3: The association of methylation and mRNA expression status of MAGE-A1 in $14 \mathrm{GC}$ cell lines. $p=0.0012$ is calculated by chi-square test.

but not as a determinant of apoptosis to taxane therapy [26,27]. While the mechanism by which MAGE-A1 confers docetaxel resistance is still unclear, several studies have reported that MAGE family proteins bind and promote EID (E1A-like inhibitor of differentiation) family of proteins, such as EID-2 [28,29]. EID-2 is known to inhibit TGF-beta promoting NF-kB activation [30,31]. We hypothesize that MAGE-A1 could indirectly activate anti-apoptotic NF-kB through its interaction with EID2.

Aberrant expressions of specific $\beta$ tubulin isotypes and its microtubule associated proteins (MAPs) correlate with drug resistance to tubulin targeting drugs in a range of cancers $[32,33]$. Docetaxel inhibits tubulin depolymerisation by binding to the pocket of $\beta$ tubulin subunits causing stabilization of microtubules leading to disruption of normal mitotic spindle formation and inhibition of cell division at the G2-M phase of the cell cycle [34,35]. The observation that MAGE-A1 knockdown cells are more sensitive to docetaxel, but not non-tubulin targeting drugs such as cisplatin and 5-fluorouracil, have led us to examine the effect of MAGE-A1 knockdown on the dynamics of $\beta$ III tubulin and microtuble associated protein. In this study, we demonstrated that the loss of MAGE-A1 expression increased $\beta$ III tubulin expression and disorganization in the microtubule cytoskeleton network of $\beta$ tubulin in response to docetaxel. While there are conflicting reports on the role of $\beta$ III tubulin expression and docetaxel resistance, overexpression of $\beta$ III tubulin has been associated with better clinical survival [36], and improved response to docetaxel [37].

Microtubule associated protein 4 (MAP4) has been shown to interact closely with tubulins to regulate microtubule dynamics leading to microtubule stabilisation [33]. Studies have shown that overexpression of MAP4 can increase microtubules polymerization $[38,39]$ thereby increasing drug sensitivity to stabilizing tubulin agenst such as docetaxel [40]. In this study, it was observed that the loss of MAGE-A1 resulted in the overexpression of MAP4 and increased sensitivity to docetaxel. Furthermore in vitro studies had demonstrated that the loss of MAP4 increased paclitaxel resistance, while overexpressing MAP4 cells were sensitive to paclitaxel and tended to induce cellular apoptosis [38]. Our study concurs with Zhang et al., where docetaxel-treated cell lines that had low MAGE-A1 level but high MAP4 expression undergo cellular apoptosis in response to increased sensitivity to docetaxel. Collectively, these observations provide evidence of MAGE-A1 interactions with the $\beta$ tubulin family and microtubule proteins MAP4, in regulating microtubule dynamics in response to the stabilizing effects of docetaxel.

MAGE-A1 expression is thought to be regulated epigenetically by promoter methylation and histone acetylation. Promoter methylation at the 5' end of MAGE-A1 gene inhibits the activator binding sites, thereby leading to the transcriptional repression of MAGE-A1 activity [41]. In several types of cancers, promoter hypermethylation of MAGE-A1 is associated with downregulation of MAGE-A1 expression [42]. Conversely, hypomethylation of MAGE-A1 promoter leads to increased MAGE-A1 expression [8,43,44]. In addition, the expression of MAGE-A1 has been suggested to be regulated via histone acetylation
[3], involving interactions between nuclear protein SKIP and HDAC1 [45].

In this study, we found that gastric cancer cell lines that had methylated MAGE-A1 gene were strongly associated with silencing of MAGE-A1 and increased docetaxel sensitivity. Furthermore, demethylation of MAGE-A1, with a demethylating agent, restored MAGE-A1 expression, but not with a HDAC inhibitor. Similar findings were reported by Honda et al., where a direct correlation of methylation to gene expression of MAGE-A1 and -A3 was found in 10 gastric cancer cell lines, supporting the role of methylation in regulating MAGE-A1 expression [8]. Therefore our data suggested that docetaxel response in gastric cancer cell lines may be dependent on the level of MAGE-A1 expression, which in turn is epigenetically regulated by promoter methylation.

In summary, we have demonstrated that MAGE-A1 expression was associated with docetacel resistance in gastric cancer, and this expression was regulated by DNA promoter demethylaton not histone acetylation. In addition, knockdown of MAGE-A1 led to reversal of docetaxel resistance and increased apoptopsis via p53 independent pathway. To the best of our knowledge this is first report demonstrating that the loss of MAGE-A1 can result in increased expression of $\beta I I I$ tubulins and MAP4, and altered microtubule structure. Our work provides an explanation as to why MAGE-A1 knockdown increased docetaxel sensitivity but did not affect non-microtubule targeting drugs such as cisplatin and 5FU.

\section{Grant Support}

This work is supported by Grant NMRC/TCR/001-NUH/2007 from National Medical Research Council, Singapore.

\section{References}

1. De Plaen E, Arden K, Traversari C, Gaforio JJ, Szikora JP, et al. (1994) Structure, chromosomal localization, and expression of 12 genes of the MAGE family. Immunogenetics 40: 360-369.

2. Weeraratne SD, Amani V, Neiss A, Teider N, Scott DK, et al. (2011) miR 34 a confers chemosensitivity through modulation of MAGE-A and p53 in medulloblastoma. Neuro Oncol 13: 165-175.

3. Wischnewski F, Pantel K, Schwarzenbach H (2006) Promoter demethylation and histone acetylation mediate gene expression of MAGE-A1, -A2, -A3, and -A12 in human cancer cells. Mol Cancer Res 4: 339-349.

4. Yoshimatsu T, Yoshino I, Ohgami A, Takenoyama M, Hanagiri T, et al. (1998) Expression of the melanoma antigen-encoding gene in human lung cancer. $J$ Surg Oncol 67: 126-129.

5. Pereira CM, Gomes CC, De Fátima Correia Silva J, Bucciarelli Rodriguez M, Barbosa AA, et al. (2012) Evaluation of MAGE A1 in oral squamous cell carcinoma. Oncol Rep 27: 1843-1848.

6. Ogata K, Aihara R, Mochiki E, Ogawa A, Yanai M, et al. (2011) Clinica significance of melanoma antigen-encoding gene-1 (MAGE-1) expression and its correlation with poor prognosis in differentiated advanced gastric cancer. Ann Surg Oncol 18: 1195-1203.

7. Szatanek R, Drabik G, Baran J, Kolodziejczyk P, Kulig J, et al. (2008) Detection of isolated tumour cells in the blood and bone marrow of patients with gastric cancer by combined sorting, isolation and determination of MAGE-1, -2 mRNA expression. Oncol Rep 19: 1055-1060.

8. Honda T, Tamura G, Waki T, Kawata S, Terashima M, et al. (2004) Demethylation of MAGE promoters during gastric cancer progression. $\mathrm{Br}$ Cancer 90: 838-843.

9. Kim KH, Choi JS, Kim IJ, Ku JL, Park JG (2006) Promoter hypomethylation and reactivation of MAGE-A1 and MAGE-A3 genes in colorectal cancer cell lines and cancer tissues. World J Gastroenterol 12: 5651-5657.

10. Suzuki T, Yoshida K, Wada Y, Hamai Y, Sentani K, et al. (2007) Melanoma- 
Citation: Xie C, Liem N, Wong FY, Yan FL, Yong WP (2013) Loss of Melanoma-associated Antigen-A1 (MAGE-A1) Reverses Docetaxel Resistance and Increases Apoptosis via p53-independent Pathway in Gastric Cancer. J Carcinog Mutagen S6: 006. doi:10.4172/2157-2518.S6-006

associated antigen-A1 expression predicts resistance to docetaxel and paclitaxel in advanced and recurrent gastric cancer. Oncol Rep 18: 329-336.

11. Nardiello T, Jungbluth AA, Mei A, Diliberto M, Huang X, et al. (2011) MAGE-A inhibits apoptosis in proliferating myeloma cells through repression of Bax and maintenance of survivin. Clin Cancer Res 17: 4309-4319.

12. Bazin IS, Kanagavel D, Nasyrova Rlu, Garin AM, Tiuliandin SA (2009) [Docetaxel in the treatment of metastatic gastric cancer]. Vestn Ross Akad Med Nauk 8: 26-28.

13. Nishiyama M, Wada S (2009) Docetaxel: its role in current and future treatments for advanced gastric cancer. Gastric Cancer 12: 132-141.

14. Tetzlaff ED, Cheng JD, Ajani JA (2008) Review of docetaxel in the treatment of gastric cancer. Ther Clin Risk Manag 4: 999-1007.

15. Van Cutsem E, Moiseyenko VM, Tjulandin S, Majlis A, Constenla M, et al. (2006) Phase III study of docetaxel and cisplatin plus fluorouracil compared with cisplatin and fluorouracil as first-line therapy for advanced gastric cancer: a report of the V325 Study Group. J Clin Oncol 24: 4991-4997.

16. Fujiwara $\mathrm{Y}$, Takiguchi S, Nakajima K, Miyata H, Yamasaki M, et al. (2011) Intraperitoneal docetaxel combined with S-1 for advanced gastric cancer with peritoneal dissemination. J Surg Oncol 105: 38-42.

17. Ajani JA, Moiseyenko VM, Tjulandin S, Majlis A, Constenla M, et al. (2007) Clinical benefit with docetaxel plus fluorouracil and cisplatin compared with cisplatin and fluorouracil in a phase III trial of advanced gastric or gastroesophageal cancer adenocarcinoma: the V-325 Study Group. J Clin Oncol 25: 3205-3209.

18. Jordan MA, Wilson L (2004) Microtubules as a target for anticancer drugs. Nat Rev Cancer 4: 253-265.

19. Hayashi Y, Kuriyama H, Umezu H, Tanaka J, Yoshimasu T, et al. (2009) Class III beta-tubulin expression in tumor cells is correlated with resistance to docetaxel in patients with completely resected non-small-cell lung cancer. Intern Med 48: 203-208.

20. Urano N, Fujiwara Y, Doki Y, Kim SJ, Miyoshi Y, et al. (2006) Clinical significance of class III beta-tubulin expression and its predictive value for resistance to docetaxel-based chemotherapy in gastric cancer. Int J Oncol 28 : 375-381.

21. Yang B, O'Herrin S, Wu J, Reagan-Shaw S, Ma Y, et al. (2007) Select cancer testes antigens of the MAGE-A, -B, and -C families are expressed in mast cell lines and promote cell viability in vitro and in vivo. J Invest Dermatol 127: 267-275

22. Gascoigne KE, Taylor SS (2009) How do anti-mitotic drugs kill cancer cells? J Cell Sci 122: 2579-2585.

23. Mhaidat NM, Wang Y, Kiejda KA, Zhang XD, Hersey $P$ (2007) Docetaxelinduced apoptosis in melanoma cells is dependent on activation of caspase-2. Mol Cancer Ther 6: 752-761.

24. Zhao J, Li QQ, Zou B, Wang G, Li X, et al. (2007) In vitro combination characterization of the new anticancer plant drug beta-elemene with taxanes against human lung carcinoma. Int $\mathrm{J}$ Oncol 31: 241-252.

25. Gan L, Wang J, Xu H, Yang X (2011) Resistance to docetaxel-induced apoptosis in prostate cancer cells by p38/p53/p21 signaling. Prostate.

26. Scatena CD, Stewart ZA, Mays D, Tang LJ, Keefer CJ, et al. (1998) Mitotic phosphorylation of Bcl-2 during normal cell cycle progression and Taxolinduced growth arrest. J Biol Chem 273: 30777-30784.

27. Ling $\mathrm{YH}$, Tornos C, Perez-Soler R (1998) Phosphorylation of Bcl-2 is a marke of $\mathrm{M}$ phase events and not a determinant of apoptosis. J Biol Chem, 273: 18984-18991.

28. Hudson JJ, Bednarova K, Kozakova L, Liao C, Guerineau M, et al. (2011)
Interactions between the Nse3 and Nse4 components of the SMC5-6 complex identify evolutionarily conserved interactions between MAGE and EID Families. PLoS One 6: e17270.

29. Guerineau M, Kriz Z, Kozakova L, Bednarova K, Janos P, et al. (2012) Analysis of the Nse3/MAGE-binding domain of the Nse4/EID family proteins. PLoS One 7: e35813.

30. Lee HJ, Lee JK, Miyake S, Kim SJ (2004) A novel E1A-like inhibitor of differentiation (EID) family member, EID-2, suppresses transforming growth factor (TGF)-beta signaling by blocking TGF-beta-induced formation of Smad3Smad4 complexes. J Biol Chem 279: 2666-2672.

31. Ray A, Dhar S, Ray BK (2010) Transforming growth factor-beta1-mediated activation of NF-kappaB contributes to enhanced ADAM-12 expression in mammary carcinoma cells. Mol Cancer Res 8: 1261-1270.

32. Sève $P$, Dumontet $C(2008)$ Is class III beta-tubulin a predictive factor in patients receiving tubulin-binding agents? Lancet Oncol 9: 168-175

33. Kavallaris M (2010) Microtubules and resistance to tubulin-binding agents. Nat Rev Cancer 10: 194-204.

34. Wang LG, Liu XM, Kreis W, Budman DR (1999) The effect of antimicrotubule agents on signal transduction pathways of apoptosis: a review. Cancer Chemother Pharmacol 44: 355-361.

35. Jordan MA, Toso RJ, Thrower D, Wilson, L (1993) Mechanism of mitotic block and inhibition of cell proliferation by taxol at low concentrations. Proc Natl Acad Sci U S A 90: 9552-9556.

36. Aoki D, Oda Y, Hattori S, Taguchi K, Ohishi Y, et al. (2009) Overexpression of class III beta-tubulin predicts good response to taxane-based chemotherapy in ovarian clear cell adenocarcinoma. Clin Cancer Res 15: 1473-1480.

37. Galmarini CM, Treilleux I, Cardoso F, Bernard-Marty C, Durbecq V, et al. (2008) Class III beta-tubulin isotype predicts response in advanced breast cancer patients randomly treated either with single-agent doxorubicin or docetaxel. Clin Cancer Res 14: 4511-4516.

38. Zhang CC, Yang JM, White E, Murphy M, Levine A, et al. (1998) The role of MAP4 expression in the sensitivity to paclitaxel and resistance to vinca alkaloids in p53 mutant cells. Oncogene 16: 1617-16124.

39. Zhang CC, Yang JM, Bash-Babula J, White E, Murphy M, et al. (1999) DNA damage increases sensitivity to vinca alkaloids and decreases sensitivity to taxanes through p53-dependent repression of microtubule-associated protein 4. Cancer Res 59: 3663-3670.

40. Hait WN, Yang JM (2006) The individualization of cancer therapy: the unexpected role of p53. Trans Am Clin Climatol Assoc 117: 85-101.

41. De Smet C, Courtois SJ, Faraoni I, Lurquin C, Szikora JP, et al. (1995) Involvement of two Ets binding sites in the transcriptional activation of the MAGE1 gene. Immunogenetics 42: 282-290.

42. Zhang J, Yu J, Gu J, Gao BM, Zhao YJ, et al. (2004) A novel protein-DNA interaction involved with the $\mathrm{CpG}$ dinucleotide at -30 upstream is linked to the DNA methylation mediated transcription silencing of the MAGE-A1 gene. Cell Res 14: 283-294.

43. Xiao J, Chen HS, Fei $R$, Cong X, Wang LP, et al. (2005) Expression of MAGE-A1 mRNA is associated with gene hypomethylation in hepatocarcinoma cell lines. J Gastroenterol 40: 716-721.

44. Yanagawa N, Tamura G, Oizumi H, Endoh M, Motoyama T (2011) MAGE expressions mediated by demethylation of MAGE promoters induce progression of non-small cell lung cancer. Anticancer Res 31: 171-175.

45. Laduron S, Deplus R, Zhou S, Kholmanskikh O, Godelaine D, et al. (2004) MAGE-A1 interacts with adaptor SKIP and the deacetylase HDAC1 to repress transcription. Nucleic Acids Res 32: 4340-4350. 